\title{
ASPECTS OF SOUND COMMUNICATION IN SOME CARIBBEAN REEF FISHES (EUPOMACENT RUS SPEC., PISCES: POMACENTRIDAE)
}

\author{
by \\ HELMUT ALBRECHT \\ Laboratory of Animal Behaviour, University of Amsterdam, The Netherlands
}

\begin{abstract}
Four species of sympatric damselfishes (Eupomacentrus, Pomacentridae) from certain Florida reefs can be distinguished by certain sound characteristics used during courtship. Apparently the fish use these characteristics for species recognition. These characteristics involve the temporal structure of a sound, i.e. the length of the pulse interval, containing the necessary code for communication.

In Curaçao members of the same species did not use the same sound characteristics for species recognition as in Florida. Strangely enough, some were able to differentiate between local congeners, but unable to recognize members of their own species. The question arises whether local dialects are in different codes, in different parts of the species' distribution range. These populations could live in local restricted areas, as recordings from one species suggest. It is possible that apart from the temporal structure, the frequency spectrum carries important information for the identification of the species in question. This contradicts earlier conclusions.
\end{abstract}

\section{ZUSAMMENFASSUNG}

In Florida unterscheiden sich 4 sympatrische Fischarten in ihren Balz-Lauten. Die Fische benutzen offenbar dieselben Unterschiede zur Arterkennung. Die Unterschiede betreffen die Pulsintervalle innerhalb eines Lautes.

In Curaçao unterscheiden dieselben Arten nicht die Laute der Fische von Florida, wohl aber bei lokal aufgenommenen Lauten andere Arten als die eigene. Es könnte sein, dass die Tiere Lokaldialekte haben, die nur in Florida die Pulsintervalle als wichtigstes Unterscheidungsmerkmal zeigen. Dagegen sprechen Unterschiede in der Zeitstruktur des Balzlautes einer Art, aber von verschiedenen Stellen in Florida. Es könnte sein, dass Lokaldialekte von Riff zu Riff verschieden sind. Es könnte sein, dass sich innerhalb jeder Art die Frequenzen der Laute unterscheiden. Damit werden frühere Annahmen widersprochen.

\section{INTRODUCTION}

The damselfish (Pomacentridae) are a large family of marine shallow-water fish, found all around the world. Its members are small and often colourful. All occur in stable, patchy environments, mostly as part of the vast tropical reef community. Consequently intra- and interspecific behaviour responses, as well as responses to the environment have evolved to a very great extent, as witnessed by an ever increasing number of field and laboratory studies. While most studies are done on the optic modality and, to a lesser extent, on the olfactory modality, more and more studies are devoted to the acoustic modality as a means for guiding inter- and intraspecific behaviour. The present paper falls within this last category. Specimens from Curaçao of each species used in this study (E. planifrons, E. partitus, E. dorsopunicans, E. leucostictus), are incorporated in the ichthylogical collection of the Institute of Taxonomic Zoology, University of Amsterdam.

Damselfish of the genus Eupomacentrus are one of the most ubiquitous groups of fishes of the Caribbean reefs (fig. 1). Its 9 or more species are all active sound producers, particularly as means of communication during their courtship behaviour (Emery, 1968; Myrberg, 1971, 1972abc; Myrberg et al., 1978; Spanier, 1979). Tavolga (1956, 1958 ) was among the first to give evidence of the function of sounds of several fish species in reproductive behaviour, and Moulton (1958) describes sounds of Eupomacentrus leucostictus in a territorial and reproductive context. To Myrberg (1972abc), among others, we owe studies on the specificity of the signals involved. E. partitus, according to Myrberg \& Spires (1972), can discriminate temporal differences between 5 and $10 \mathrm{msec}$. These studies were probably stimulated by Winn (1964), who suggested that the coding of information may be through temporal patterning, since so many of the sounds produced by different fish species are so similar. Most sounds are short stridulatory pulses with a fundamental near $100 \mathrm{~Hz}$; harmonic tones like the ones of the toad fish (Opsanus tau) being the exception. 


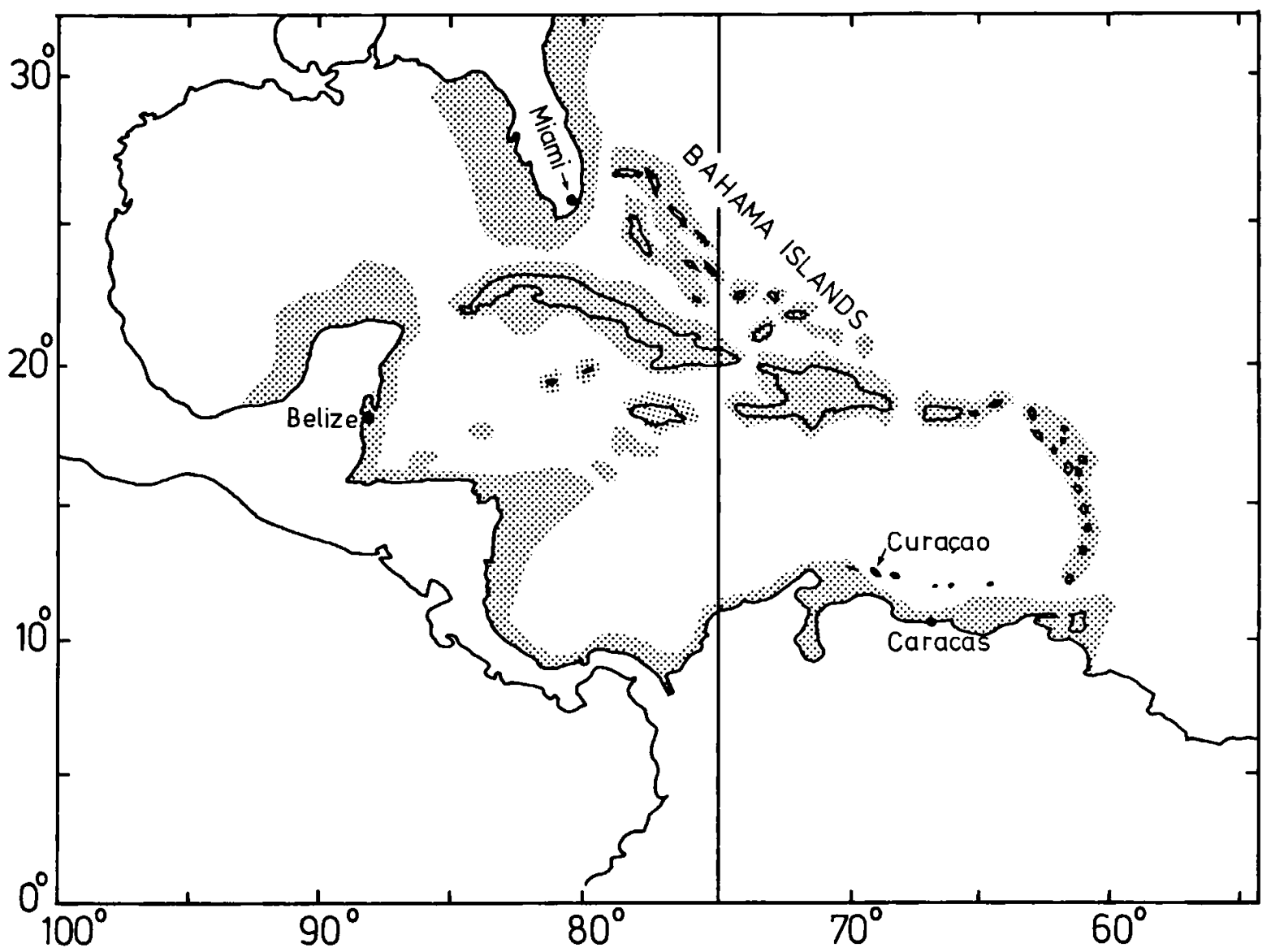

Fig. 1. Caribbean reef area. Pomacentrids occur in most parts of it.

\section{TERMINOLOGY}

The sounds under investigation can be discriminated by pitch (fundamental frequency), intensity (amplitude, dB), quality (harmonics, carrier frequencies), duration and repetition rate.

It should be noted that a tone, in the physical sense, consists of only one frequency, whereas in musicology and in the present study tones or sounds are characterized by pitch and quality. Quality often includes a combination of disharmonic sounds, i.e. noises.

The duration of a sound, if it consists of pulses, depends on the number of pulses, the duration of each pulse and the interval between each pulse.

On the sonagrams used (B/65 wide band, $160-16000 \mathrm{~Hz}$, Kay Sonagraph), pitch and intensity were discernable from various shades of grey. The quality could not be differentiated, whereas aspects of the time structure (i.e. pulse interval) were analysed in msec.

\section{EQUIPMENT}

Sound recording and processing systems included the following instruments: a hydrophone (CIC US navy), tape recorders: Uher (1000 pilot and 4000 report) and Nagra (IVSJ), an underwater speaker ( $Y$ Square Marine Inc., yack/yack) and a sonagraph (Kay Electric).

Recordings in Bimini were done with Uher and in Cura- çao with Nagra. Playback in Curaçao with Nagra. All sonagrams were made using Nagra. Minimal variations of recording speed of Uher as compared to Nagra were taken into account with the final interpretation of the results. The choice of this equipment was based on the following considerations:

Tavolga (1965) and Schneider (1967) warn against difficulties of spectral analysis of underwater sound, especially if the acoustic conditions are not specified and controlled. Our hydrophones and loudspeakers did not correspond to the best possible acoustical characteristics. However, since not the spectral quality, but the time structure was assumed to be of decisive importance, and the frequency less or even not at all (Myrberg et al., 1978, see also discussion), we adjusted our equipment to these two ends: high precision in speed stability, i.e. time structure, and less precision in the frequency characteristics of some links in our string of equipment. At any rate, the tonal quality of the recorded and transduced sounds was indistinguishable to the author's ear from sounds heard in the field.

\section{THE PROBLEM}

The four species used in our experiments (Eupomacentrus leucostictus, E. dorsopunicans, E. par- 


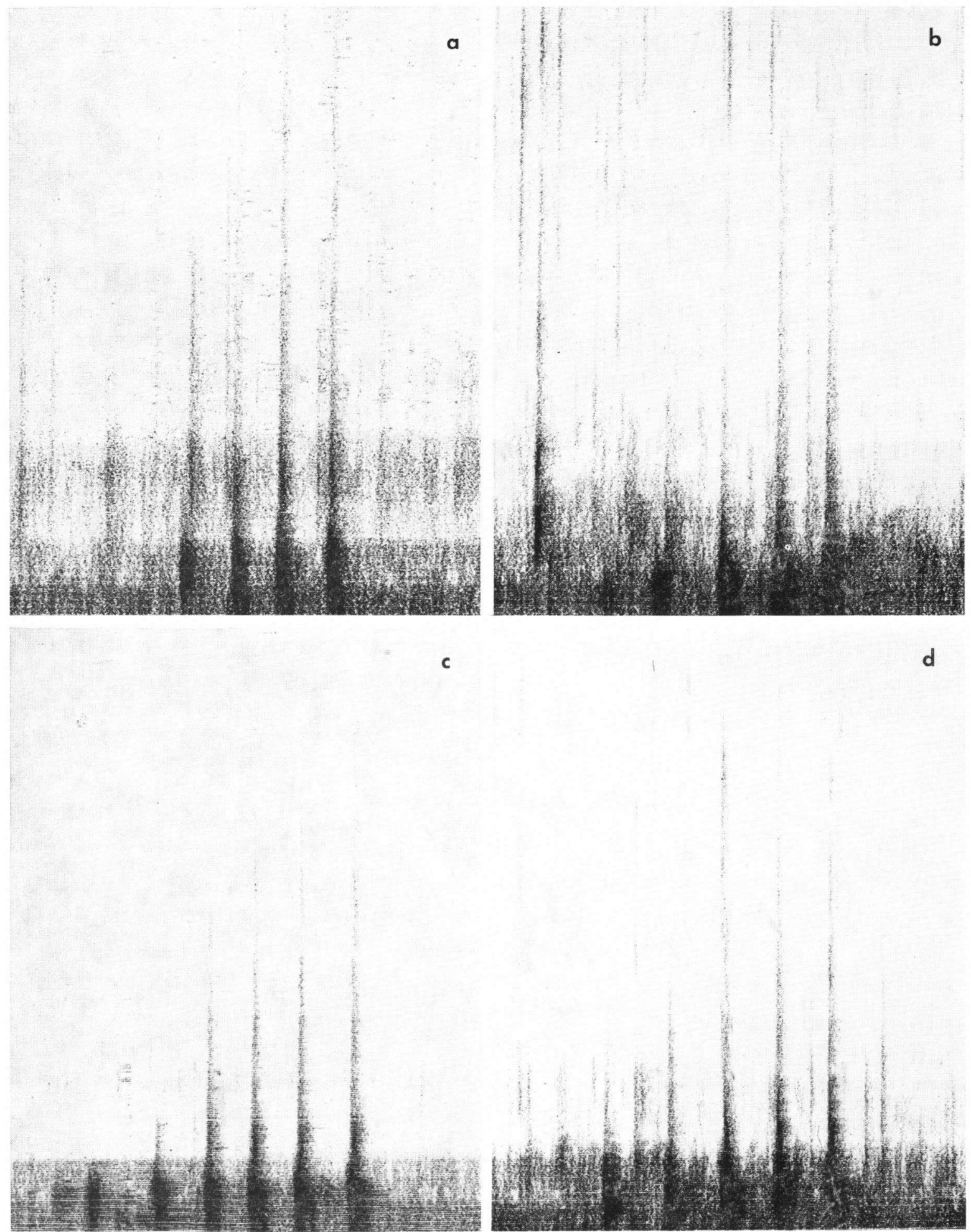

Fig. 2. Sonagrams of Eupomacentrus partitus (a), E. planifrons (b), E. leucostictus (c) and E. dorsopunicans (d) from Curaçao. 
titus, E. planifrons) appear to have a common reproductive season and overlapping ecological niches. They often maintain residences and territories within a few meters of one another (Emery, 1968). Apparently, the males produce similar sounds at the same moment during their almost identical courtship movements (fig. 2). Such sounds readily bring forth courtship behaviour in nearby male conspecifics (Myrberg et al., 1978), so that such sounds must have a function in species recognition at a crucial moment. Myrberg et al. (1978) have also shown in their experiments that the sounds produced by members of each species can be heard by members of all the others. Recognition by vision seems unlikely, not only because the species in question show very similar locomotory behaviour patterns during courting, but also because each species, being differently coloured during their daily routine activities, become similarly coloured during courting. So far nobody has been searching for cues in species recognition in the optical or, for that matter, in the olfactory field. Sound seemed the most promising beginning.

Winn (1964) discusses several important principles, when he categorized signal sounds of fishes into variable interval, fixed interval, unit duration and harmonic frequency: most sounds, if not all, are different in their temporal patterning, and this is the feature that may communicate information during courtship, territorial defence and reaction to predators. This information can be graded by varying the intervals and length of units. Amplitude and frequency characteristics do not seem to contain enough information.

Marler (1967) puts the following questions about a signal in a presumed communication link: (1) are there correlations between variations in the properties of the signal and variations in the patterns of response, and (2) is a particular part, a property of a signal, responsible for evoking a given response? In other words: a signal code is necessary to avoid confusion when communicating (Konishi, 1970; Marler, 1974). The experimental results of Myrberg (1972b) on one of the pomacentrid species ( $E$. partitus) answer these questions. They show clearly that this species is able to react differently upon various sounds of con- specifics (similar in frequency spectrum but different in temporal structure) in a consistent manner.

Myrberg \& Spires (1972) also demonstrated that $E$. partitus showed significantly different responsiveness to homologous sounds, similar in frequency and time structure, but coming from three species, its own and two congeners. The similarity was based on a widely overlapping range in the frequency spectra and temporal differences in the order of milliseconds. The reactions allow the conclusion that individuals of this species are able to "recognize" certain sounds.

The next step is to investigate if all species in question can differentiate between the sounds of conspecifics and those so very similar ones of sympatric congeners. Myrberg et al. (1978) concluded that of all parameters investigated the most important cues for species recognition were the time structure of a courtship sound, in particular the pulse duration and, even more important, the pulse interval. Spanier (1979), apparently using the same data, comes to comparable conclusions. In addition to the pulse interval he also found the pulse number to be effective. Differences in milliseconds were decisive in attracting conspecifics for reproduction instead of "others". There are no other obvious ecological or ethological isolating factors to prevent hybridization. Any genetic or physiological factors imply a waste of time and/or energy, in terms of reproduction (Meise, 1936) or in terms of fitness (Dawkins, 1976). Mayr (1942, 1963) discusses hybridization within the concept of speciation at length. There are no hybrids known so far within the genus Eupomacentrus. One can expect a strong selection pressure favouring any isolating mechanism that helps to maintain species identity with so many mutual characters (almost same niches, courtship movements, -sounds and -colouration).

Myrberg et al. (1972, 1978) deny the importance of frequency characteristics in communication. Contrary to time structure elements, frequencies show widely overlapping ranges between the species. They range up to $2500 \mathrm{~Hz}$, with most intensity concentrated between 250 and $1100 \mathrm{~Hz}$. The highest intensity of the sounds of the various species was below $800 \mathrm{~Hz}$, almost identical in each 
species and without clear peaks. It is interesting to note that the sensory capacity of adult fish does not go above $800 \mathrm{~Hz}$ either (Myrberg, in prep.). This could mean that subadult fish, producing sounds $>800 \mathrm{~Hz}$, are to some extent excluded from reproduction.

As with any study, an answer to a question poses new questions: Myrberg et al. (1978) took their experimental animals from a place in the neighbourhood of their laboratory, near Key Biscayne, Florida. Key Biscayne is part of a chain of many islands that runs from Miami Beach to Key West. These islands form a continuous reef system, $250 \mathrm{~km}$ long, within which members of Eupomacentrus can probably easily interchange. Myrberg did some initial experiments in Bimini, Bahamas, a small island across the Straits of Florida. It is doubtful if much interchange occurs with the Eupomacentrus populations of the Florida Keys and the Bahamas $50 \mathrm{~km}$ across the strong Florida Current. Nonetheless, Myrberg et al. (1978) concluded a zoogeographical uniformity of both populations because the findings were consistent in both places. At any rate, recordings from Curaçao, $2000 \mathrm{~km}$ more to the south, are likely to be from different Eupomacentrus populations, and if those populations use the same sound characteristics for species recognition as the ones in Florida, then we should get the same experimental results as in Florida.

We wanted to investigate this hypothesis by playing back sounds of the four species in question to all four species and by comparing the reactions upon these sounds. The sounds were recorded on Bimini (Bahamas) and on Curaçao. In a second step, specific components of the sounds from the two localities (including recordings of one species, E. leucostictus, from Pigeon Key, Florida Keys) were analysed.

The experiments in Curaçao were conducted using SCUBA in Oct.-Nov. 1975, on the south coast of the island in the surroundings of the Caribbean Marine Biological Institute, Piscadera Bay. In Bimini, only sounds were recorded during summer 1967.

\section{EXPERIMENTAL PROCEDURE}

Sounds for playback were selected, as in Myrberg's studies, upon clarity, i.e. on the basis of a low level of ambient noise accompanying the given sounds. Since the fish under investigation occur in the habitats of snapping shrimps (Alpheus sp.) which create a high frequency din during most of the day, several hundreds of sounds of each species were recorded in order to select the best ones. These sounds were recorded on tape loops so that they could be played back with a repetition rate of ca. 25 sounds/min; S. Ha (unpublished dissertation, University of Miami, 1973; in Myrberg et al., 1978) based this choice on the sound rate of their experimental animals during intensive courtship activities. They considered an increase of the call rate by $10 / \mathrm{min}$ to $25 / \mathrm{min}$ as a cue for courtship intensity. Because the number of pulses within each call varies, and the greatest responsiveness is shown to those calls having the species specific typical number of pulses, Myrberg et al. (1978) used calls with the typical number for each species. For $E$. dorsopunicans this was 6-7, for $E$. planifrons 4 , for $E$. leucostictus 4 and for E. partitus 3.

In the present study the same numbers were used in the experiments with sounds from the Bahamas. In the experiments with sounds from Curaçao itself, many different sounds ( $N=43$ $E$. dorsopunicans, $\mathrm{N}=42 \mathrm{E}$. leucostictus, $\mathrm{N}=$ 57 E. partitus, $\mathrm{N}=70 \mathrm{E}$. planifrons) were presented on a continuous tape within the playback period; in this way the repetition rate was irregular, varying from 20 to $35 / \mathrm{min}$ in each experiment and the pulse number was not always the typical one. The order in which the sounds were played was randomized.

The experimental species were $E$. dorsopunicans (13 $\hat{o} \hat{o}), E$. partitus ( $5 \hat{o} \hat{o}$ ) and $E$. planifrons (3 $\hat{\delta} \hat{o}$ ). The number of experiments were 96, 29 and 12, respectively. Experiments were conducted during a time of the year (Oct./Nov.) when frequent courtship was evidenced in the field, and during a time of day (ca. 10.00$14.00 \mathrm{hrs}$ ) when no great fluctuations in courtship activities occurred. Myrberg et al. (1978) and Spanier (1979) did their experiments (between 10.00-14.00 hrs) during a greater part of the year (May-August).

The loudspeaker was placed on the border of 
a given male's territory. Since the size of the territory varied from less than one to several $\mathrm{m}^{2}$, the distance of the loudspeaker to the experimental fish also varied. However, the intensity of a given sound was roughly the same as that given by the experimental animals. According to $\mathrm{Ha}$ (unpublished dissertation, in Myrberg et al., 1978) an exactly natural sound level is not necessary. This can be expected on the basis of differences in territory size. In both studies the courtship sounds made by males were reacted upon not only by females, but also by males. Because the reaction of passing females, ready to spawn, was too unpredictable and, therefore, time consuming, the frequent and reliable reactions of neighbouring males on courting males were used to assess the value of experimental sounds. Standard playback periods of $3 \mathrm{~min}$ (Myrberg et al., 1978) and 2 min in the present study were altered with equally long control periods of silence. Various behaviour patterns were recorded during the experiments, like movements, sounds, colour patterns. The socalled "dip", a particular movement in reaction to the sounds under investigation, was the most easy to discern and therefore reliable to record. For detailed description of the behaviour patterns, see Myrberg (1972b).

The data are accessible on request from the author or from the editorial secretary of Bijdragen tot de Dierkunde.

\section{RESULTS}

Experiments, in which sounds of Bahamian populations of E. leucostictus, E. planifrons, E. dorsopunicans and $E$. partitus were played back to $E$. dorsopunicans and E. partitus in Curaçao, gave negative results with regard to the working hypothesis. There was no difference in behaviour of territorial males (nor of females) between playback periods and control periods of silence. If we can extrapolate from a limited number of recordings (tape loops with single calls) and a limited number of experimental animals (4-6) to the two species as a whole, then a zoogeographical uniformity with regard to sound recognition in these two Eupomacentrus species apparently does not exist. Our preliminary conclusion was that there could either be differences in certain sound characteristics of the populations in the two localities or that different characteristics were being used for species recognition in the two localities. We began investigating this question by presenting three species in Curaçao with conspecific and congeneric sounds recorded from the same area.

The experimental animals reacted mostly with aggression (chasing of congenerics and others) and a little with the courtship "dip" to the various sounds presented, as compared to control periods of silence. E. dorsopunicans showed chasing during sounds of $E$. leucostictus 75 times and

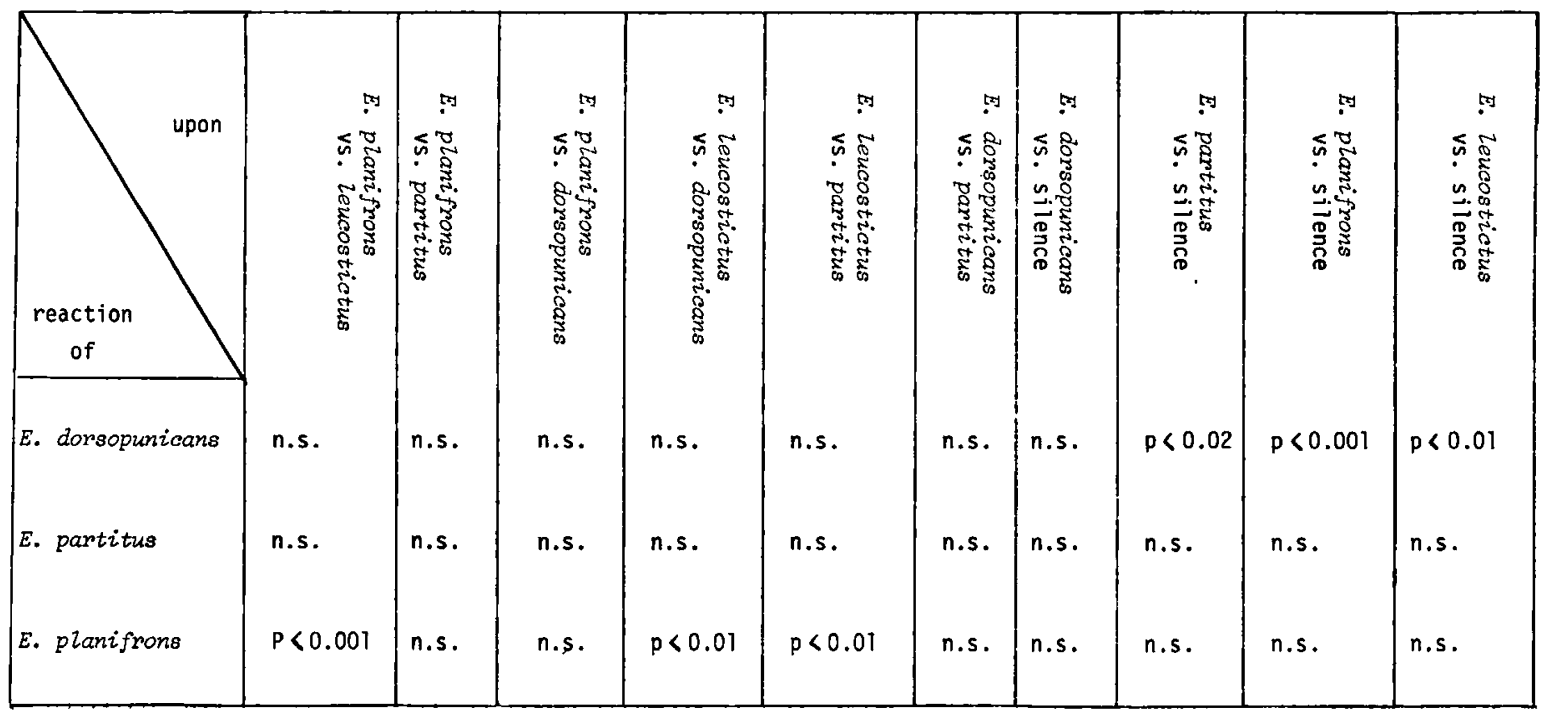

Fig. 3. Results of playback experiments in Curaçao. (Chi square test.) 


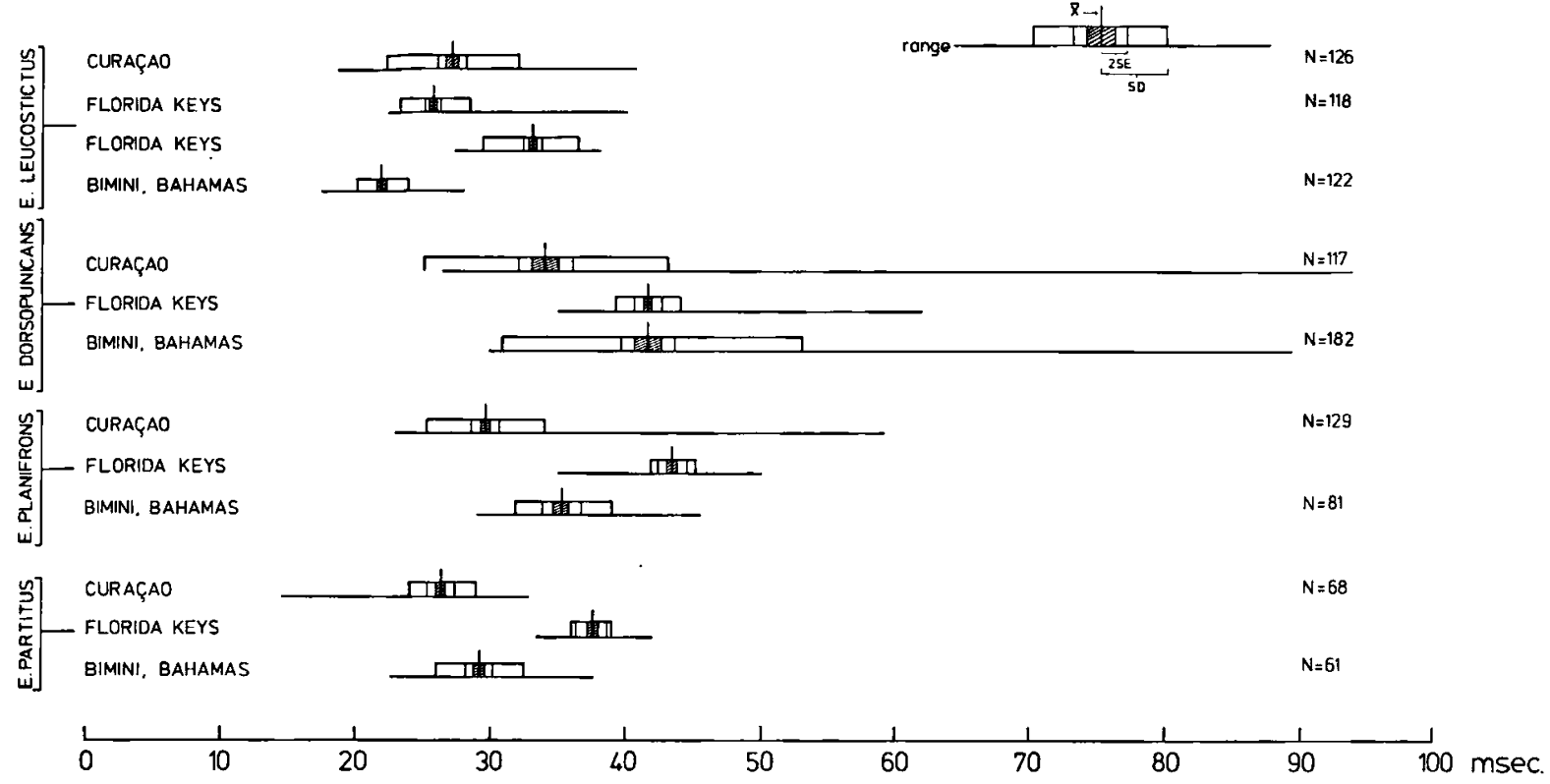

Fig. 4. Variations of pulse intervals within the courtship sounds of Eupomacentrus spec. The data where no " $\mathrm{N}$ " is given, are from Myrberg et al. (1978). $\bar{x}=$ mean, $S E=$ standard error, $S D=$ standard deviation. When two mean values were more than 2 SE apart their significance was estimated at $\leqslant 0.05$.
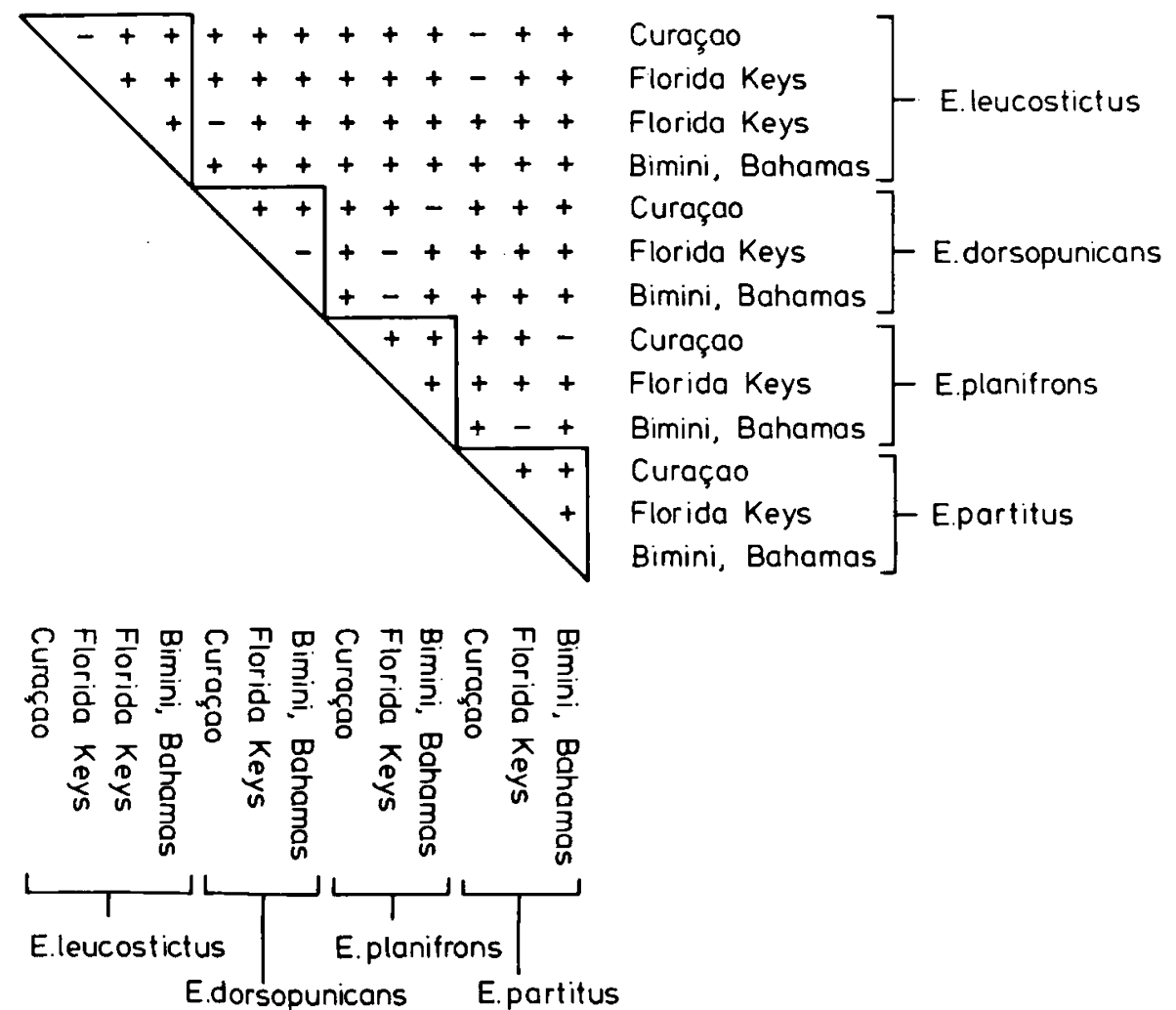

Fig. 5. Comparison of pulse intervals from various localities. Significant differences shown as "+". Statistical treatment as for fig. 4. 
during silence 40 times, during sounds of $E$. dorsopunicans 60 and during silence 33 , during sounds of $E$. partitus 74 and during silence 47 , during sounds of $E$. planifrons 53 and during silence 18 . $E$. partitus showed chasing during sounds of $E$. leucostictus 13 times and during silence 12, during sounds of E. dorsopunicans 11 and to silence 7, during sounds of $E$. partitus 13 and during silence 26, during sounds of $E$. planifrons 18 and during silence 11. E. planifrons showed chasing during sounds of E. leucostictus 2 times and during silence 6 times, during sounds of $E$. dorsopunicans 12 and during silence 10 , during sounds of $E$. partitus 11 and during silence 11, during sounds of $E$. planifrons 18 and during silence 9. Courtship occurred not frequently enough during the experiments to be treated statistically.

Concerning aggressive reactions (fig. 3) E. dorsopunicans showed no difference in reaction to the sounds of the four species. E. planifrons discriminated between $E$. planifrons and $E$. leucostic$t u s$, between $E$. leucostictus and $E$. dorsopunicans and between $E$. leucostictus and $E$. partitus. $E$. dorsopunicans discriminated between $E$. leucostictus and "silence" and between $E$. partitus and "silence". E. leucostictus can be considered the best "discriminandum" and E. planifrons the best "discriminator".

Of the 30 possible combinations there were 12 where, according to the hypothesis, a difference could be expected. However, in only one case (E. planifrons) there was such a difference $(E$. planifrons vs. leucostictus). The other differences were in combinations where one would not have expected them. It is difficult to understand why members of one species react differently to homologous characters of other species but not those of their own species.

A time structure analysis of the sounds, in particular (1) the pulse interval and (2) the pulse number, from Bimini, Bahamas (including one of the Florida Keys) and of Curaçao was undertaken.

(1) The pulse interval: A zoogeographical uniformity, as concluded by Myrberg et al. (1978) for the Florida Keys and the Bahamas, is not apparent between the Bahamas and Curaçao (fig. 4). The data for E. leucostictus from Pigeon Key
ELEUCOSTICTUS

CURAÇAO

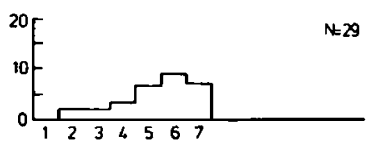

FLORIDA KEYS

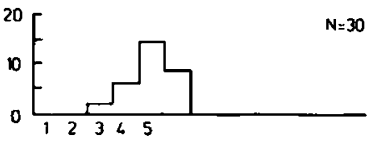

FLORIDA KEYS

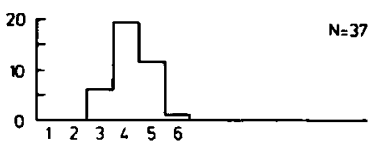

BIMINI, BAHAMAS

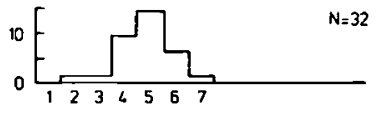

E DORSOPUNICANS

CURACAO

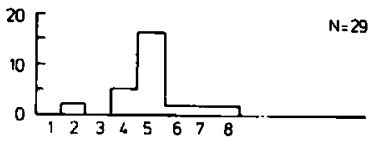

FLORIDA KEYS

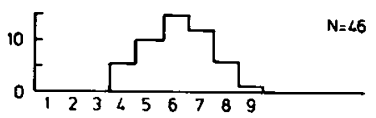

BIMINI. BAHAMAS

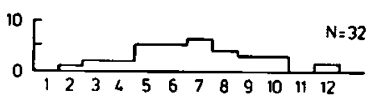

E PLANIFRONS

CURAÇAO

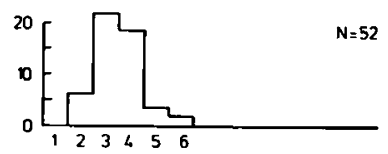

FLORIDA KEYS

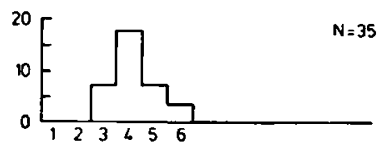

BIMINI. BAHAMAS

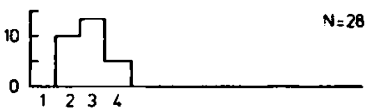

E.PARTITUS

CURAÇAO

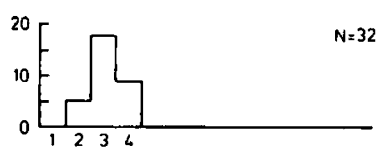

FLORIDA KEYS

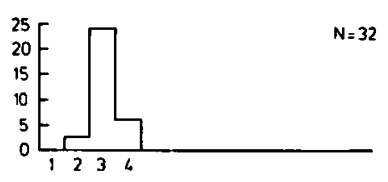

BIMINI. BAHAMAS

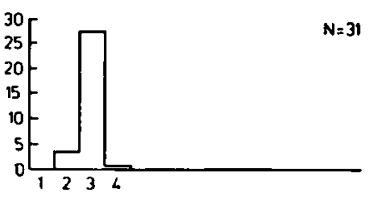

Fig. 6. Variation of pulse numbers within courtship sounds. Data from Myrberg et al. (1978) in the same sequence as in fig. 4. 

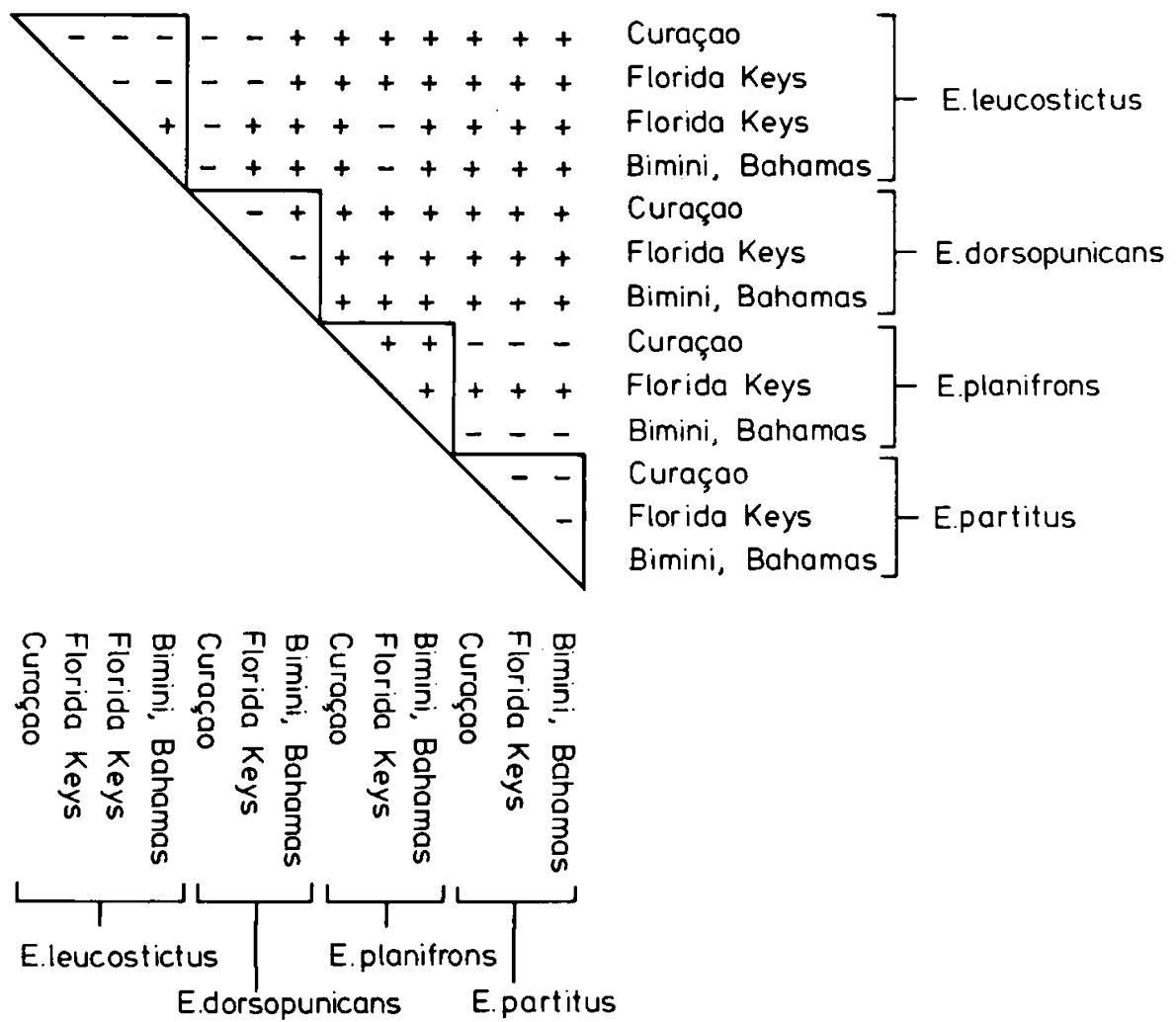

Fig. 7. Comparison of pulse numbers from various localities. Statistical treatment as for figs. 4 and 5 .

in the Florida Keys indicate that for this species there is not even uniformity within the Florida Keys. In summarizing the differences (fig. 5) we find that of 15 combinations, which according to our hypothesis should not differ, 13 are different and that of 63 combinations which should be different 8 are not. Of these, however, only two combinations (E. partitus/E. leucostictus in Curaçao and $E$. planifrons/E. dorsopunicans in the Florida Keys) were of the same locality.

(2) For the pulse number (figs. 6, 7) we find that 10 out of 15 combinations support our hypothesis and 14 out of 63 do not support it. Out of these 14 we find 4 combinations in the same locality (E. dorsopunicans/E. leucostictus in Curaçao, E. dorsopunicans/E. leucostictus in the Florida Keys, $E$. planifrons/E. partitus in Curaçao and E. planifrons/E. partitus in Bimini). The pulse number seems more in support of our hypothesis than the pulse interval. However, its importance, with the available evidence, does not yet seem to be clear.

\section{DISCUSSION}

Myrberg et al. (1978) do not mention where exactly their recordings and experiments have been done. If a species recognition mechanism, as discovered by Myrberg et al. (1978), is to operate within the whole species, then one must expect, in the light of the significant differences shown in fig. 4, a large variety of "dialects". Those dialects could be very local, as the differences for one species within one continuous area, the Florida Keys, suggest. It is possible that the puzzling results, as presented in fig. 3 , explain themselves when future recordings from interjacent areas become known.

This line of research should not inhibit alternative solutions to the problem of species recognition and/or species-specific communication, or prevent us from looking at the available data more closely. Already Tavolga (1977) notes that in $E$. partitus the discrimination of conspecific and congeneric sounds is strongly error prone. The 
conclusion of Myrberg et al. (1978), that the pulse interval is responsible for differential responsiveness to sounds of various species seems too generalized. In their experiments (see also Spanier, 1979) it was the pulse number for $E$. dorsopunicans against $E$. planifrons and vice versa. For $E$. dorsopunicans, against $E$. partitus and against $E$. leucostictus, it could be the pulse interval, the pulse number or some other uninvestigated factor. The same applies to E. leucostictus and E. partitus: they differentiate between sounds of their own species and the three others. The pulse number is considered to be responsible, howcver the pulse interval could also be. E. partitus even discriminated $E$. dorsopunicans against $E$. leucostictus and/or E. planifrons. This fact strongly resembles the allospecific discriminators in fig. 3 and equally suggests that future recordings will have to be carefully mapped because of the possibility of local dialects.

The strongest argument in support of the conclusions of Myrberg et al. (1978) that pulse interval rather than pulse number is important for species recognition, comes from the experiment in which reaction to sounds of conspecifics and artificially altered sounds of other species were compared. This modification consisted of lengthening the pulse interval (i.e. the offtime) so that it equalled the pulse interval of conspecifics: E. dorsopunicans were confronted with sounds of conspecifics, with sounds of E. leucostictus and with modified sounds of $E$. leucostictus. The result was clear: E. dorsopunicans could not differentiate between sounds of conspecifics and the modified sounds.

Is it justified to generalize these data for the whole species and even for the other three species? It seems not yet. So far, a common causal factor within a species recognition and/or communication system cannot be ascertained; some results are suggestive. What else can we go and look for? There could be other characteristics in the sounds of these fish that are responsible for their specific reaction. The present author e.g. had no difficulties in distinguishing the four species on their sound alone up to a distance of about $10 \mathrm{~m}$. It is almost certain that the measurable differences of msec are not responsible for this, because a sound of a given species seemed exactly the same in various parts of the Caribbean, i.e. Florida Keys, Bahamas, Jamaica, Colombia and Lesser Antilles. These audible differences could only be characterized in terms of harsh, soft, mellow, bright, etc., qualities which I could not detect, let alone measure, on the sonagrams. If the fish are sensitive to the same qualities, then this line of research deserves priority above the search for possible dialects.

\section{ACKNOWLEDGEMENTS}

This report forms part of studies supported by the Biology Branch, Office of Naval Research (Nonr 840 (13) and N $00014-67-A-0201-0004)$ and by the Netherlands Foundation for the Advancement of Tropical Research (WOTRO), The Hague. Further thanks are due to Dr. I. Kristensen, Caribbean Marine Biological Institute (CARMABI), Curaçao, Netherlands Antilles; Dr. R. Mathewson, Lerner Marine Laboratory of the American Museum of Natural History, Bimini, Bahamas; and Prof. Dr. A. Myrberg, Rosenstiel School of Marine and Atmospheric Science, University of Miami, Florida, U.S.A. for their kind hospitality; Prof. Dr. H. Schneider, Zoological Institute, University of Bonn, German Federal Republic, for his specialist advice on bioacoustical matters and to Dr. S. Weinberg, Institute of Taxonomic Zoology, Amsterdam, The Netherlands, for diving assistance. Special thanks go to the head of the department, Prof. Dr. J. H. Stock, Institute of Taxonomic Zoology, Amsterdarn, The Netherlands, for his permanent support during all phases of this study and also to J. P. Abell, H. van der Meyden, Dr. B. A. Heuts, S. van Mechelen, A. Pistoor, F. Weinberg, C. Zwikker, and not in the least to A. Rol, Free University, Amsterdam, Dept. of Systematic Zoology, for making the sonagrams.

\section{REFERENCES}

DawkINs, R., 1976. The selfish gene: 1-224 (Oxford Univ. Press, Oxford).

EMERY, A. R., 1968. Comparative ecology of damselfishes (Pisces: Pomacentridae) at Alligator Reef, Florida Keys: 1-260 (Diss. Univ. Miami, Fla.).

KoNishi, M., 1970. Evolution of design features in coding of species specificity. Am. Zoologist, 10: 67-72.

MARLER, P., 1967. Animal communication signals. Science, 157: 769-774.

-, 1974. Animal communication. In: L. Kramer, T. AlLOWAY \& P. Pliner eds., Non verbal communication: 25-50 (Plenum Press, New York, London).

MAYR, E., 1942. Systematics and the origin of species: 1.334 (Dover Publs., New York).

- 1963. Populations, species and evolution: $1-453$ (Belknap, Cambridge, Mass.).

Meise, W., 1936. Ueber Artentstehung durch Kreuzung in der Vogelwelt. Biol. Zentralbl., 56: $590-604$.

Moulton, J. M., 1958. The acoustical behavior of some fishes in the Bimini area. Biol. Bull., 114: 357-374.

MYrberg, A. A., 1971. Hearing and allied senses in fishes. Final Rep. nation. Sci. Found.: 1-52.

- 1972a. Using sound to influence the behavior of freeranging marine animals. In: H. E. WINN \& B. L. Olla 
eds., Behavior of marine animals, 2: $435-468$ (Plenum Press, New York, London).

-, 1972b. Ethology of Bicolor Damselfish, Eupomacentrus partitus (Pisces: Pomacentridae): a comparative analysis of laboratory and field behavior. Anim. Beh. Monogr., 5: 197-283.

- 1972c. Social dominance and territoriality in the $\mathrm{Bi}$ color Damselfish, Eupomacentrus partitus (Poey) (Pisces: Pomacentridae). Behaviour, 41: 207-231.

Myrberg, A. A., E. Spanier \& S. Ha, 1978. Temporal patterning in acoustical communication. In: E. S. REESE \& F. Lighter eds., Contrasts in behavior: 137-179 (John Wiley, Chichester, England; Sommerset, U.S.A.).

Myrberg, A. A. \& J. Y. SpIres, 1972. Sound discrimination by the Bicolor Damselfish, Eupomacentrus partitus. J. expl. Biol., 57: 727-735.

SCHNEIDER, H., 1967. Morphology and physiology of sound producing mechanisms in teleost fishes. In: W. N. TAvolgA ed., Marine bio-acoustics, 2: 135-158 (Pergamon, Oxford).
Spanier, E., 1979. Aspects of species recognition by sound in four species of damselfishes, genus Eupomacentrus (Pisces: Pomacentridae). Z. Tierpsych., 51: 301-316.

Tavolga, W. N., 1956. Visual, chemical and sound stimuli as cues in the sex discriminatory behavior of the gobiid fish, Bathygobius soporator. Zoologica, 41: 49-64.

- 1958. The significance of underwater sounds produced by males of the gobiid fish, Bathygobius soporator. Phys. Zool., 31: 259-271.

- 1965. Review of marine bio-acoustics. State of the art: 1964. Techn. Rep. 1212-1 (U.S. nav. Train. Dev. Center, Wash., N.Y.).

1977. Recent advances in the study of sound production in fishes. In: W. N. TAvolga, ed., Sound production in fishes: 47-53. Benchmark Animal Behavior, 9 (Dowden, Hutchinson \& Ross, Stroudsburg, Pa., U.S.A.).

WINN, H. E., 1964. The biological significance of fish sounds. In: W. N. TAvolga ed., Marine bio-acoustics, 2: 213-231 (Pergamon, Oxford).

Received: 18 December 1980 